Case Reports in
Gastroenterology
Case Rep Gastroenterol 2021;15:262-268

DOI: 10.1159/000513147

Published online: March 3, 2021
(C) 2021 The Author(s)

Published by S. Karger AG, Base www.karger.com/crg

This article is licensed under the Creative Commons Attribution-NonCommercial 4.0 International License (CC BY-NC) (http://www.karger.com/Services/OpenAccessLicense). Usage and distribution for commercial purposes requires written permission.

\title{
Unusual Presentation of Anal Pain and Tenesmus from Rectal Arteriovenous Malformation Successfully Treated with Ethanol Sclerotherapy
}

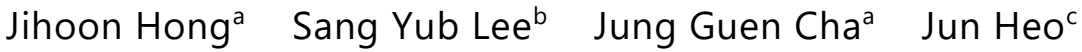 \\ aDepartment of Radiology, Kyungpook National University Hospital, Daegu, Republic of \\ Korea; ${ }^{b}$ Department of Radiology, School of Medicine, Kyungpook National University, \\ Daegu, Republic of Korea; 'Department of Internal Medicine, School of Medicine, \\ Kyungpook National University, Daegu, Republic of Korea
}

\section{Keywords}

Arteriovenous malformation $\cdot$ Rectum $\cdot$ Tenesmus $\cdot$ Anal pain $\cdot$ Transarterial ethanol sclerotherapy

\begin{abstract}
Gastrointestinal arteriovenous malformation (AVM) is reported as one of the possible causes of intestinal bleeding, and its occurrence in the rectum is rare. We report the case of a rectal AVM patient who experienced uncommon symptoms of anal pain and tenesmus and was treated successfully with percutaneous transarterial ethanol sclerotherapy. The patient underwent routine colonoscopy with biopsy at the time of visit; however, an accurate diagnosis was difficult. Subsequent contrast-enhanced computed tomography (CT) and angiography revealed a rectal AVM emerging from the distal inferior mesenteric artery with engorged superior rectal veins. The feeding artery was catheterized, and concurrent transarterial sclerotherapy with $80 \%$ ethanol was performed. There was no major complication related to the procedure. Disappearance of AVM nidus and improvement of associated venous congestion were shown by follow-up CT. There was no recurrence of symptoms after 10 months of clinical observation.
\end{abstract}

\begin{tabular}{ll}
\hline & Sang Yub Lee \\
Department of Radiology, Kyungpook National University Hospital \\
130 Dongdeok-ro, Jung-gu \\
Daegu 41944 (Republic of Korea) \\
Isyrad@gmail.com
\end{tabular}




\section{Case Reports in Gastroenterology}

Case Rep Gastroenterol 2021;15:262-268 DOI: $10.1159 / 000513147$

(c) 2021 The Author(s). Published by S. Karger AG, Basel www.karger.com/crg

Hong et al.: Rectal AVM Successfully Treated with Ethanol Sclerotherapy

Transarterial ethanol sclerotherapy is safe and effective in treating rectal AVM and can be considered as one of the nonsurgical treatment options.

\section{Introduction}

Arteriovenous malformation (AVM) of the gastrointestinal tract is recognized as one of the potential causes of intestinal bleeding. Among them, rectal AVM is very rare, and its incidence is reported as $0.9-14 \%$ of all intestinal AVMs [1, 2]. Anal bleeding and anemia are the main symptoms of rectal AVM, and the diagnosis of rectal AVM is difficult with routine colonoscopy alone if abnormal vascular structures are not located in the mucosal surface. Computed tomography (CT) can show the location and complexity of the AVM, while angiography is the most reliable diagnostic modality and a less invasive method that allows to perform endovascular treatment simultaneously [2]. Recently, cases in whom rectal AVM was successfully treated by transcatheter embolization using various embolic materials have been reported [2-5]. A rare case of rectal AVM treated with transarterial ethanol sclerotherapy, manifested as unusual symptoms of anal pain and tenesmus, is reported here.

\section{Case Report}

A 64-year-old male patient was admitted to our hospital's gastroenterology department. The patient had no specific medical history, except for dyslipidemia, and complained of rectal tenesmus, lasting for 1 month, and anal pain, which had progressively worsened for 10 days. At the time of arrival, stool occult blood test was negative and no relevant findings in other laboratory results were identified. An 8-mm polyp in the ascending colon was detected during colonoscopy, and hyperemic mucosal swelling with nodularity was noted at $4-17 \mathrm{~cm}$ from the anal verge (Fig. 1a). Biopsies performed for each lesion indicated adenoma and chronic colitis, respectively. Diffuse swelling throughout the rectum was seen on CT, and engorgement of the superior rectal veins with early draining was also observed (Fig. 1b, c). AVM-related venous hypertension was suspected as the cause of symptoms, and angiography was requested. On angiography performed 3 days later, rectal AVM was identified at the inferior mesenteric artery just before the beginning of the superior rectal arteries and was drained via fine feeders into the inferior mesenteric vein with a large venous aneurysm (Fig. 2a). Venous regurgitation by venous hypertension was also clearly observed through the retrograde flow of the superior rectal veins (Fig. 2b). After an in-depth discussion with the patient about the options for surgery or other endovascular embolization, transarterial sclerotherapy using ethanol was decided. After selection to the far distal feeding artery using a microcatheter, sclerotherapy was performed several times using a total of $5 \mathrm{~mL}$ of $80 \%$ ethanol (Fig. 2c, d), while shunt was gradually reduced in serial follow-up angiography. To prevent venous thrombosis, 2,000 units of heparin were intravenously administered during the procedure. The early arteriovenous shunt was completely lost in completion angiography, and a little spasm was observed in the distal branch of the superior rectal arteries (Fig. 2e). The spasm improved after intra-arterial infusion of 1,000,000 units of nitroglycerin, and the procedure was terminated. There were no acute complications except for analgesic-controlled buttock pain. Follow-up CT performed 2 weeks later revealed reduced rectal wall edema, AVM nidus disappearance, and thrombosed

\section{Karger'=}




\section{Case Reports in Gastroenterology}

Case Rep Gastroenterol 2021;15:262-268

DOI: $10.1159 / 000513147$

(c) 2021 The Author(s). Published by S. Karger AG, Basel www.karger.com/crg

Hong et al.: Rectal AVM Successfully Treated with Ethanol Sclerotherapy

venous sac (Fig. 3). In addition, engorgement and early draining of the superior rectal veins were also lost. The main symptoms, such as rectal tenesmus and anal pain, gradually improved within 1 week of hospitalization and did not recur during clinical follow-up for 10 months.

\section{Discussion}

A case of AVM that occurred in the rectum, an infrequent location, was identified and presented as unusual symptoms. With transarterial ethanol sclerotherapy, we effectively treated this disease.

Gastrointestinal tract AVM is a rare disease and is reported to account for $0.8-3.0 \%$ of the causes of intestinal bleeding [1]. Several gastrointestinal AVMs occur in the right colon and are rarer in the rectum [6]. To explain this disease, congenital or acquired causes are considered, and there are reports that divide intestinal AVMs into three types according to the patient's age, location, size, gross features, and heredity [7].

Although the typical gastrointestinal AVM symptom, including the rectum, was reported as intestinal bleeding without abdominal pain, AVM may be accompanied by various atypical symptoms. As in our case, diagnosis may be difficult when the patient has atypical symptoms, including bowel habit change or pain, which are supposed to be due to venous hypertension caused by AVM.

There are two major pathophysiologic conditions in the AVM. One is steal phenomenon, which is characterized by arterial insufficiency for rapid shunting of the arterial flow to the dominant outflow vein sparing distal perfusion. However, in the present case, angiography showed sufficient arterial flow to the rectum. The second one is AVM-related venous hypertension. Venous hypertension with venous flow congestion occurs due to arterial high blood pressure directly affecting the venous side through the AVM nidus, which appears to have been the cause of pain and tenesmus in the present patient (Fig. 1b, c). On the contrary, no rectal bleeding or anemia occurred because the AVM mainly involved the mesentery. If the engorged vein or AVM nidus is located close to the mucosal surface, rectal bleeding can be a major presenting symptom.

Since mucosal abnormalities do not always appear, the diagnosis of the gastrointestinal AVM is often difficult with routine colonoscopy and barium enema. The reported diagnosis rate of colorectal AVM through colonoscopy was only 78.8\%, whereas that of angiography was 96.5\% [1]. For accurate diagnosis, contrast-enhanced CT or conventional angiography can be helpful. Early visualization of the venous structure in arterial-phase CT image can be a clue to diagnosing AVM. Due to its real-time flow depiction of the AVM, angiography is the most reliable diagnostic modality and allows performance of concurrent embolization.

Surgery has been the main treatment for rectal AVM; however, recently successful cases of endovascular embolization have been reported [2-5]. Metallic coils, gelatin particles, microspheres, polyvinyl alcohol, N-butyl cyanoacrylate, and Onyx were used as embolic material. However, particulate embolic agents are not suitable for AVM management because those materials can pass through the AVM nidus and eventually lead to inadvertent venous embolism such as pulmonary infarction [8]. Meanwhile, coils and N-butyl cyanoacrylate can make proximal embolization, leaving the AVM nidus, which is considered a major recurrence factor after embolization. However, ethanol is an agent capable of causing vascular thrombosis, occlusion, and nidus elimination by destroying vascular endothelial cells. Ethanol sclerotherapy is a treatment that has been proven to be effective by itself or in combination with embolization

\section{Karger'=}




\section{Case Reports in Gastroenterology}

\begin{tabular}{l|l}
\hline Case Rep Gastroenterol 2021;15:262-268 \\
\hline DOI: 10.1159/000513147 & $\begin{array}{l}\text { ○ 2021 The Author(s). Published by S. Karger AG, Basel } \\
\text { www.karger.com/crg }\end{array}$ \\
\hline
\end{tabular}

Hong et al.: Rectal AVM Successfully Treated with Ethanol Sclerotherapy

and has been reported to have lower recurrence after treatment of AVM than other substances that cause mechanical obstruction [9]. Due to these features, it was a most suitable agent for resolving rectal venous congestion that caused symptoms in our patient. For the safe use of ethanol, we reduced the possibility of nontarget embolization by superselecting the feeder, and an experienced operator carefully performed the procedure. After the procedure, the patient's symptoms improved without major complications and did not recur during 10 months of clinical observation.

In conclusion, we report a case of rectal AVM treated with transarterial ethanol sclerotherapy, a rare disease with atypical symptoms. Transarterial ethanol sclerotherapy for rectal AVM was safe and effective and can be considered as one of the nonsurgical treatment options.

\section{Statement of Ethics}

This study was approved by the hospital's institutional review board. The patient provided written informed consent for publication of clinical details and images.

\section{Conflict of Interest Statement}

The authors have no conflicts of interest to declare.

\section{Funding Sources}

This research was supported by the Basic Science Research Program through the National Research Foundation of Korea (NRF) funded by the Ministry of Education, Science, and Technology (NRF-2017R1C1B5075931).

\section{Author Contributions}

Conceptualization and investigation: all authors. Formal analysis: J. Hong, S.Y. Lee, J.G. Cha. Methodology: J. Hong, S.Y. Lee, J. Heo. Resources: J.G. Cha, J. Heo. Supervision: S.Y. Lee. Writing of the original draft: J. Hong. Data curation, review, and editing: J. Hong, S.Y. Lee. All authors read and approved the final version of the manuscript.

\section{References}

1 Hayakawa H, Kusagawa M, Takahashi H, Okamura K, Kosaka A, Mizumoto R, et al. Arteriovenous malformation of the rectum: report of a case. Surg Today. 1998;28(11):1182-7.

2 Komekami Y, Konishi F, Makita K, Mijin T, Onogawa A, Chochi T, et al. Rectal arterio-venous malformation (AVM) with bleeding of an internal hemorrhoid. Clin J Gastroenterol. 2016 Feb;9(1):22-6.

3 Ishikawa S, Mukai S, Hirata Y, Kohata A, Kai A, Namba Y, et al. Rectal Arteriovenous Malformation Treated by Transcatheter Arterial Embolization. Case Rep Gastroenterol. 2020 Jan;14(1):7-14.

4 Yap HY, Lee SY, Chung YF, Tay KH, Low AS, Thng CH, et al. Rectal arterio-portal fistula: an unusual cause of persistent bleeding per rectum following a proximal spleno-renal shunt. World J Gastroenterol. 2013 Jul; 19(25):4087-90.

\section{Karger'=}




\section{Case Reports in Gastroenterology}

\begin{tabular}{l|l}
\hline Case Rep Gastroenterol 2021;15:262-268 \\
\hline DOI: 10.1159/000513147 & $\begin{array}{l}\text { @ 2021 The Author(s). Published by S. Karger AG, Basel } \\
\text { www.karger.com/crg }\end{array}$ \\
\hline
\end{tabular}

Hong et al.: Rectal AVM Successfully Treated with Ethanol Sclerotherapy

5 Pierce J, Matthews J, Stanley P, Panossian A, Ford H, Anselmo D. Perirectal arteriovenous malformation treated by angioembolization and low anterior resection. J Pediatr Surg. 2010 Jul;45(7):1542-5.

6 Meyer CT, Troncale FJ, Galloway S, Sheahan DG. Arteriovenous malformations of the bowel: an analysis of 22 cases and a review of the literature. Medicine (Baltimore). 1981 Jan;60(1):36-48.

7 Moore JD, Thompson NW, Appelman HD, Foley D. Arteriovenous malformations of the gastrointestinal tract. Arch Surg. 1976 Apr;111(4):381-9.

8 Wijeyaratne SM, Ubayasiri RA, Weerasinghe C. Fatal pulmonary embolism of polyvinyl alcohol particles following therapeutic embolisation of a peripheral arteriovenous malformation. BMJ Case Rep. 2009;2009: bcr02.2009.1635.

9 Vogelzang RL, Atassi R, Vouche M, Resnick S, Salem R. Ethanol embolotherapy of vascular malformations: clinical outcomes at a single center. J Vasc Interv Radiol. 2014 Feb;25(2):206-13.
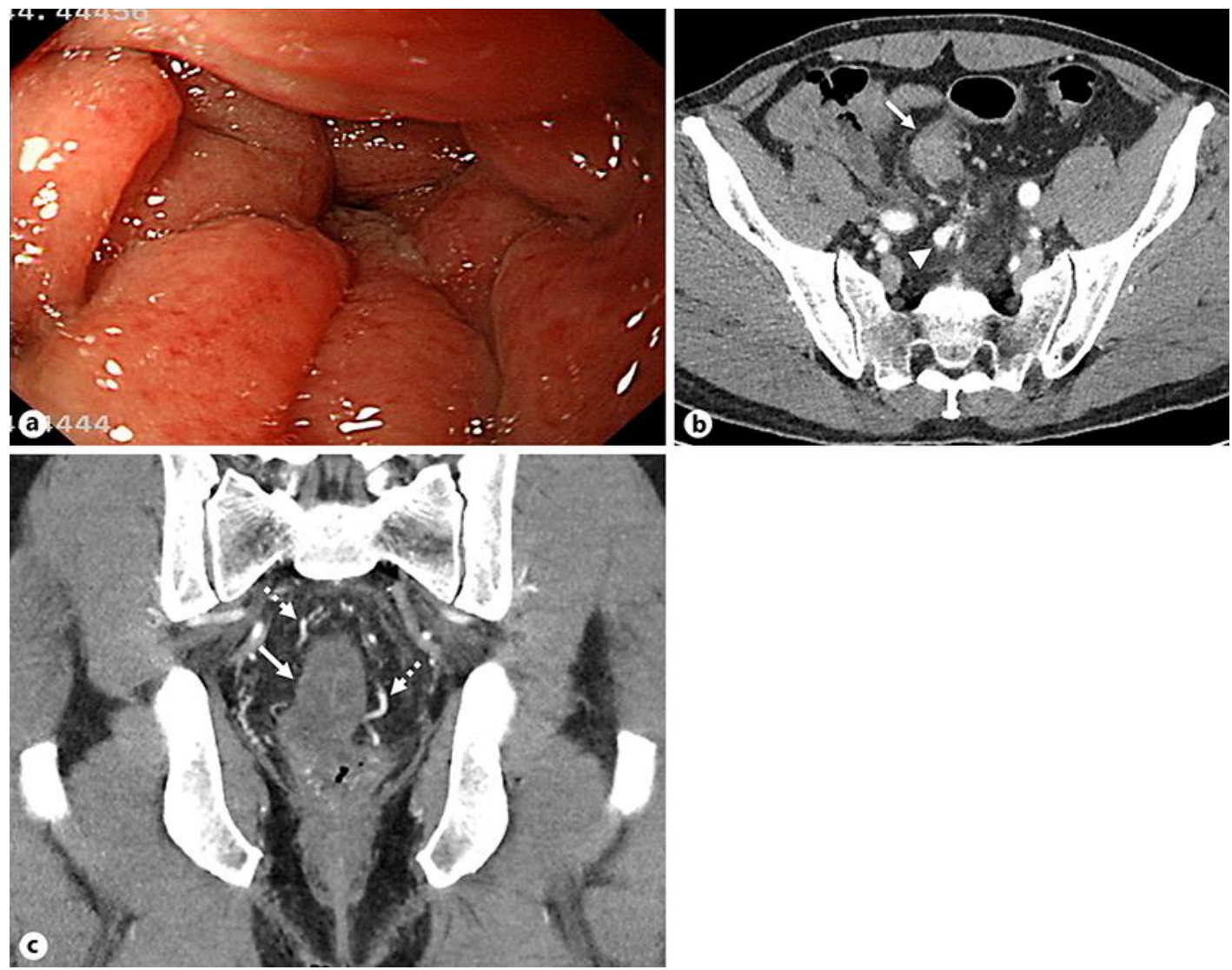

Fig. 1. Colonoscopic findings and contrast-enhanced CT images before sclerotherapy. a Colonoscopic image from the anal side shows hyperemic mucosal swelling with nodularity at the rectum. b, c Axial (b) and coronal (c) CT images demonstrate edematous rectal wall (solid arrow) and engorgement of the superior rectal veins (dotted arrows) as well as dilated venous sac (arrowhead) with early draining. CT, computed tomography.

\section{Karger'=}




\section{Case Reports in Gastroenterology}
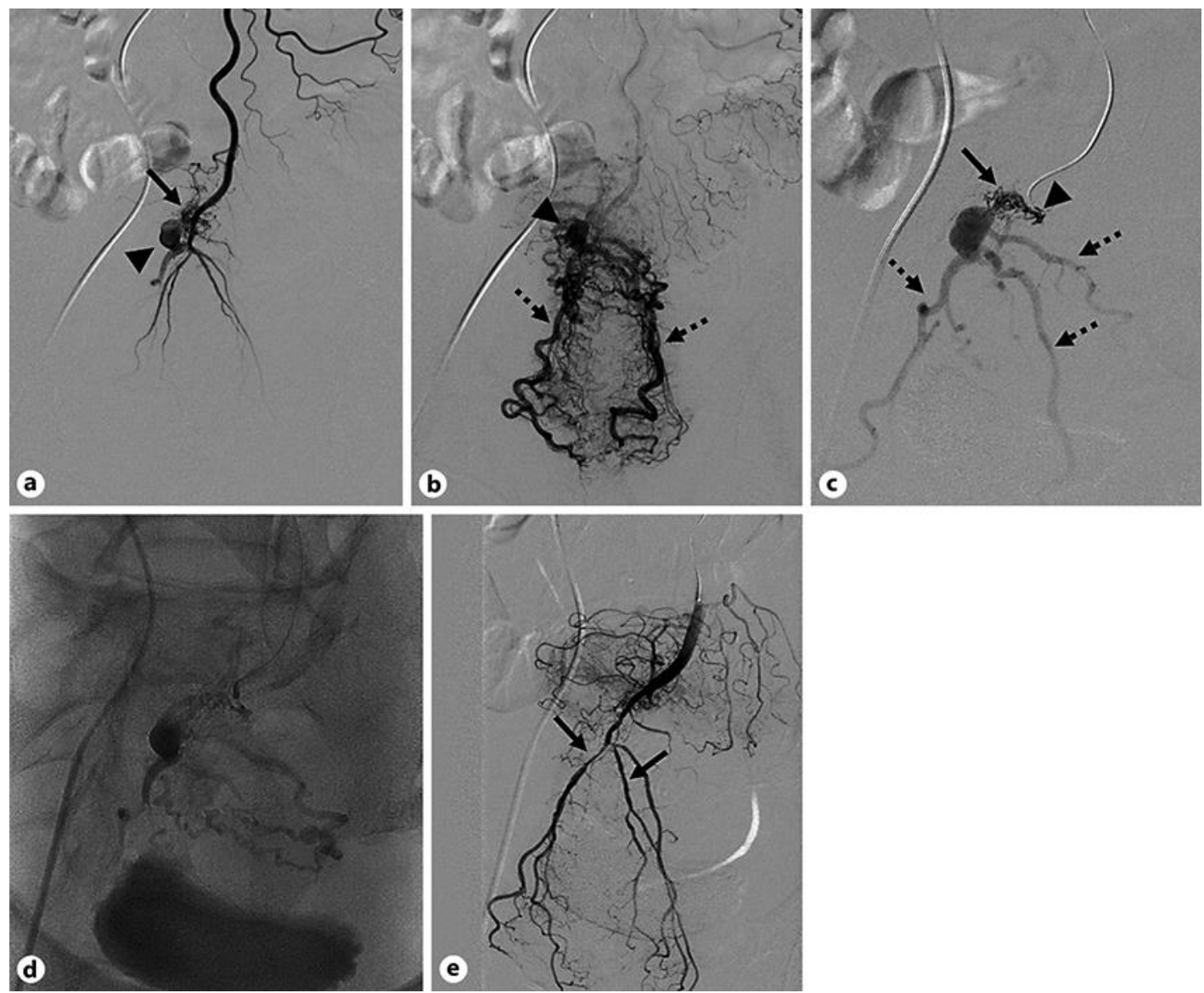

Fig. 2. Digital subtraction angiography of the inferior mesenteric artery (IMA) and concurrent transarterial ethanol sclerotherapy of rectal AVM. a, b Early arterial (a) and delayed phase (b) of the IMA angiography show rectal AVM with fine feeders and nidus (arrow) arising from the distal IMA and early visualization of dilated venous sac (arrowheads) and the superior rectal veins (dotted arrows). c Selective angiography of far distal feeding artery shows the relationship between fine feeders (arrowhead), nidus (arrow), and early draining veins (dotted arrows). d Transarterial sclerotherapy was performed using $80 \%$ ethanol. e Completion angiography revealed complete loss of nidus opacification and early arteriovenous shunt. Residual minimal spasm was noted at the superior rectal arteries (arrows). AVM, arteriovenous malformation.

\section{Karger'}


Case Reports in Gastroenterology
Case Rep Gastroenterol 2021;15:262-268

DOI: $10.1159 / 000513147$

(c) 2021 The Author(s). Published by S. Karger AG, Basel www.karger.com/crg

Hong et al.: Rectal AVM Successfully Treated with Ethanol Sclerotherapy
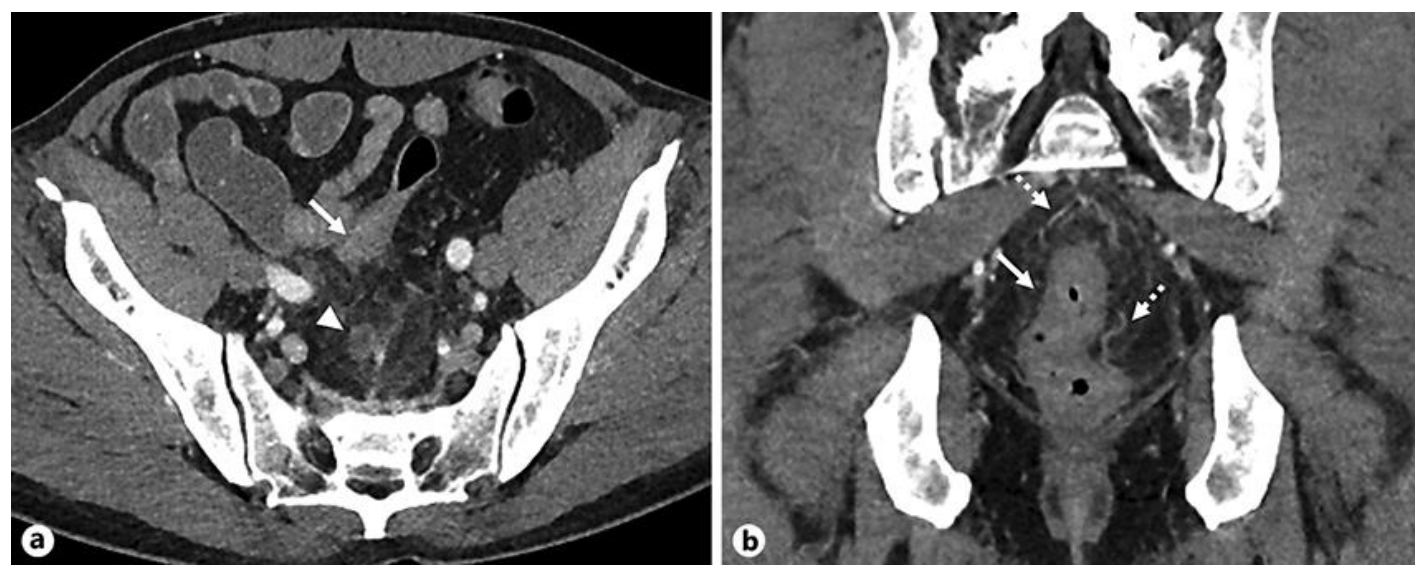

Fig. 3. Contrast-enhanced CT images 2 weeks after sclerotherapy. Axial (a) and coronal (b) CT images demonstrate decreased rectal wall edema (arrows) and size reduction of thrombosed venous sac (arrowhead). The engorgement of the superior rectal veins (dotted arrows) is resolved and early draining is no longer visible. CT, computed tomography. 